\title{
Ganirelix Acetate
}

National Cancer Institute

\section{Source}

National Cancer Institute. Ganirelix Acetate. NCI Thesaurus. Code C61774.

The acetate salt form of ganirelix, a synthetic decapeptide with high antagonistic activity against naturally occurring gonadotropin-releasing hormone $(\mathrm{GnRH})$. Ganirelix directly competes with the GnRH for receptor binding in the anterior pituitary gland, thus induces a rapid and reversible suppression of the release of follicle stimulating hormone (FSH) and luteinizing hormone (LH). This agent is used for the inhibition of premature $\mathrm{LH}$ surges in women undergoing controlled ovarian hyperstimulation, and in combination with other hormones for retrieval of the mature follicles for in-vitro fertilization. 